\title{
The Effect of Nb Content on the Thermal, Structural, and Magnetic Properties of FeNbB Ribbons
}

\author{
Z. Hua*, B. Zuo, M.Y. Li, X.N. Wang, L.L. Wang, J. Liu, D. Wang And L.R. Dong \\ Key Laboratory of Functional Materials Physics and Chemistry of the Ministry of Education \\ Jilin Normal University, Siping 136000, Jilin, P.R. China
}

(Received May 8, 2013; in final form July 30, 2013)

\begin{abstract}
Amorphous $\mathrm{Fe}_{80-x} \mathrm{Nb}_{x} \mathrm{~B}_{20}(x=5,10,15)$ ribbons were prepared by single-roller melt spinning method. The thermal, structural and magnetic properties of $\mathrm{Fe}_{80-x} \mathrm{Nb}_{x} \mathrm{~B}_{20}(x=5,10,15)$ ribbons were investigated using differential thermal analysis, X-ray diffraction, and vibrating sample magnetometer. The thermal stability is the lowest for $\mathrm{Fe}_{70} \mathrm{Nb}_{10} \mathrm{~B}_{20}$ ribbon and the highest for $\mathrm{Fe}_{65} \mathrm{Nb}_{15} \mathrm{~B}_{20}$ ribbon. Along with the increase of $\mathrm{Nb}$ content, the supercooled liquid region $\Delta T_{x}$ increases, indicating that the amorphous formation ability improves. The primary stages of crystallization of the three ribbons are different. The primary devitrification phases are $\mathrm{Fe}_{23} \mathrm{~B}_{6}$ type for $\mathrm{Fe}_{70} \mathrm{Nb}_{10} \mathrm{~B}_{20}$ and $\mathrm{Fe}_{75} \mathrm{Nb}_{5} \mathrm{~B}_{20}$ ribbons, and $\alpha$-Fe type for $\mathrm{Fe}_{65} \mathrm{Nb}_{15} \mathrm{~B}_{20}$ ribbon. $\mathrm{Fe}_{80-x} \mathrm{Nb}_{x} \mathrm{~B}_{20}(x=5,10)$ ribbons are ferromagnetic and the $\mathrm{Fe}_{65} \mathrm{Nb}_{15} \mathrm{~B}_{20}$ ribbon is paramagnetic. The saturation magnetization $\left(\boldsymbol{M}_{\mathrm{s}}\right)$ decreases with increasing $\mathrm{Nb}$ content.
\end{abstract}

DOI: $10.12693 /$ APhysPolA.125.1149

PACS: 65.60.+a, 61.43.Dq

\section{Introduction}

Fe-based amorphous and nanocrystalline soft magnetic alloys have been widely studied over the last decade [1-10]. Fe-based ribbons have good soft magnetic properties and are widely used as the electromagnetic materials. Many investigations focus on the FeNbB alloys [6-10]. The crystallization behaviors [6], crystallization process [7], and magnetic property [8] of FeNbB alloys were studied.

Itoi and Inoue [9] have reported the effect of B content on thermal stability of Fe-Nb-B alloys. Stokłosa [10] reported the influence of boron content on crystallization and magnetic properties of ternary FeNbB amorphous alloys.

The purpose of this study is to investigate the effect of $\mathrm{Nb}$ content on the thermal, structural and magnetic properties of $\mathrm{Fe}_{80-x} \mathrm{Nb}_{x} \mathrm{~B}_{20}(x=5,10,15)$ ribbons.

\section{Experimental details}

Amorphous ribbons of $\mathrm{Fe}_{80-x} \mathrm{Nb}_{x} \mathrm{~B}_{20}(x=5,10,15)$ with $4 \mathrm{~mm}$ width and $30 \mu \mathrm{m}$ thickness were obtained by the single-roller melt spinning technique at a surface velocity of $38 \mathrm{~m} / \mathrm{s}$. The microstructure was examined by X-ray diffraction (XRD, D/max $2500 / \mathrm{PC}, \mathrm{Cu} K_{\alpha}$, $\lambda=1.5406 \AA)$. The thermal analysis was investigated by differential thermal analysis (DTA, TG/DTA-6300). The magnetic property was performed by the vibrating sample magnetometer (VSM, Lake Shore M-7407).

*corresponding author; e-mail: huazhong196110@163.com

\section{Results and discussion}

Figure 1 shows the DTA curves of $\mathrm{Fe}_{80-x} \mathrm{Nb}_{x} \mathrm{~B}_{20}(x=$ $5,10,15)$ ribbons at different heating rates. The first crystallization peaks $T_{\mathrm{p}}$ of $\mathrm{Fe}_{80-x} \mathrm{Nb}_{x} \mathrm{~B}_{20}(x=5,10,15)$ amorphous ribbons obtained at different heating rates are listed in Table I. $T_{\mathrm{p}}$ increases with the increase of Nb content. The increase of $T_{\mathrm{p}}$ should be related to the fact that $\mathrm{Nb}$ has higher melting temperature than Fe. The apparent activation energy of crystallization is calculated using the Kissinger equation [11], by plotting $\ln \left(\nu / T^{2}\right)$ versus $1 / T$ (a straight line with the slope of $E / R$ ), where $R$ is the gas constant, $\nu$ is the heating rate $(\mathrm{K} / \mathrm{min})$ and $T$ is a specific absolute temperature such as crystallization peak $T_{\mathrm{p}}$.

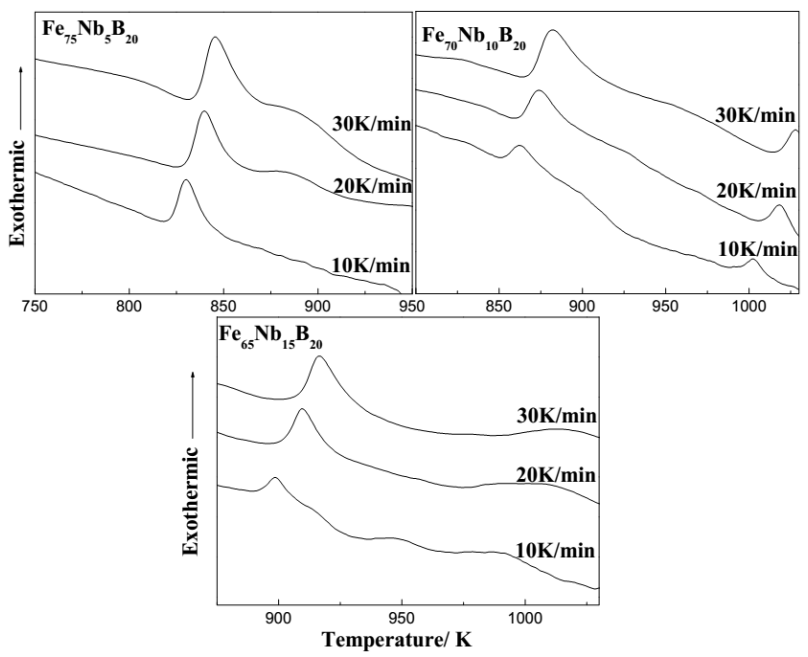

Fig. 1. DTA curves of $\mathrm{Fe}_{80-x} \mathrm{Nb}_{x} \mathrm{~B}_{20}(x=5,10,15)$ ribbons at different heating rates. 


\section{TABLE I}

The first crystallization peaks $T_{\mathrm{p}}$ of $\mathrm{Fe}_{80-x} \mathrm{Nb}_{x} \mathrm{~B}_{20}$ $(x=5,10,15)$ amorphous ribbons obtained at different heating rates.

\begin{tabular}{c|c|c|c}
\hline \hline \multirow{2}{*}{$\nu[\mathrm{K} / \mathrm{min}]$} & \multicolumn{3}{|c}{$T_{\mathrm{P}}[\mathrm{K}]$} \\
\cline { 2 - 4 } & 10 & 20 & 30 \\
\hline $\mathrm{Fe}_{75} \mathrm{Nb}_{5} \mathrm{~B}_{20}$ & 830.4 & 839.4 & 845.4 \\
$\mathrm{Fe}_{70} \mathrm{Nb}_{10} \mathrm{~B}_{20}$ & 861.7 & 873.4 & 882.4 \\
$\mathrm{Fe}_{65} \mathrm{Nb}_{15} \mathrm{~B}_{20}$ & 898.8 & 909.1 & 916.0
\end{tabular}

Figure 2 shows the Kissinger plots of $\mathrm{Fe}_{80-x} \mathrm{Nb}_{x} \mathrm{~B}_{20}$ $(x=5,10,15)$ ribbons for $T_{\mathrm{p}}$; the apparent activation energies are $414.9,323.0$, and $425.7 \mathrm{~kJ} / \mathrm{mol}$, respectively. The thermal stability is the lowest for $\mathrm{Fe}_{70} \mathrm{Nb}_{10} \mathrm{~B}_{20}$ ribbon and the highest for $\mathrm{Fe}_{65} \mathrm{Nb}_{15} \mathrm{~B}_{20}$ ribbon.

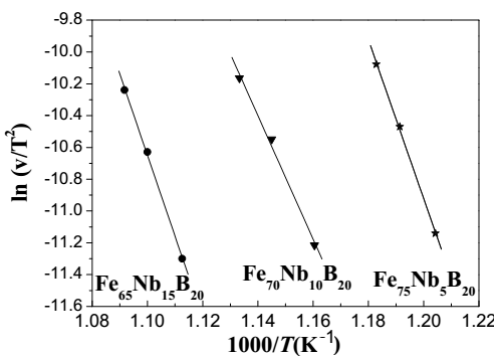

Fig. 2. Kissinger plots of $\mathrm{Fe}_{80-x} \mathrm{Nb}_{x} \mathrm{~B}_{20}(x=5,10,15)$ ribbons for $T_{\mathrm{p}}$.

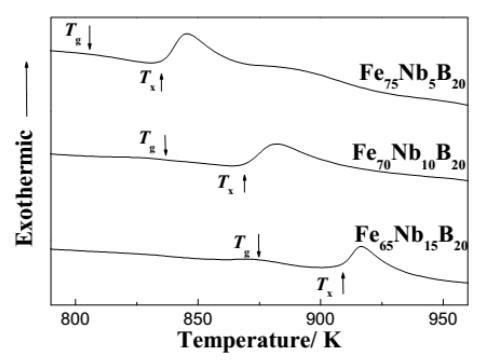

Fig. 3. DTA curves of $\mathrm{Fe}_{80-x} \mathrm{Nb}_{x} \mathrm{~B}_{20}(x=5,10,15)$ amorphous ribbons at a heating rate of $30 \mathrm{~K} / \mathrm{min}$.

Figure 3 shows the DTA curves of $\mathrm{Fe}_{80-x} \mathrm{Nb}_{x} \mathrm{~B}_{20}$ $(x=5,10,15)$ amorphous ribbons at a heating rate of $30 \mathrm{~K} / \mathrm{min}$. $T_{\mathrm{g}}, T_{x}$ and $\Delta T_{x}$ of $\mathrm{Fe}_{80-x} \mathrm{Nb}_{x} \mathrm{~B}_{20}$ $(x=5,10,15)$ amorphous ribbons at a heating rate of $30 \mathrm{~K} / \mathrm{min}$ are shown in Table II. Along with the increase of $\mathrm{Nb}$ content, the glass transition temperature $T_{\mathrm{g}}$ and the onset crystallization $T_{x}$ shift towards high temperatures. Supercooled liquid region $\Delta T_{x}\left(\Delta T_{x}=T_{x}-T_{\mathrm{g}}\right)$ increases gradually, indicating that the amorphous formation ability improves.

Figure 4 shows the XRD patterns of as-quenched and annealed $\mathrm{Fe}_{80-x} \mathrm{Nb}_{x} \mathrm{~B}_{20}(x=5,10,15)$ ribbons. No crystalline peaks are observed in the XRD patterns of three as-quenched ribbons, which prove that the as-quenched
TABLE II

$T_{\mathrm{g}}, T_{x}$ and $\Delta T_{x}$ of $\mathrm{Fe}_{80-x} \mathrm{Nb}_{x} \mathrm{~B}_{20}(x=5,10,15)$ amorphous ribbons at a heating rate of $30 \mathrm{~K} / \mathrm{min}$.

\begin{tabular}{c|c|c|c}
\hline \hline & $T_{\mathrm{g}}$ & $T_{x}$ & $\Delta T_{x}$ \\
\hline $\mathrm{Fe}_{75} \mathrm{Nb}_{5} \mathrm{~B}_{20}$ & 805.629 & 836.603 & 30.974 \\
$\mathrm{Fe}_{70} \mathrm{Nb}_{10} \mathrm{~B}_{20}$ & 833.760 & 867.931 & 34.171 \\
$\mathrm{Fe}_{65} \mathrm{Nb}_{15} \mathrm{~B}_{20}$ & 874.538 & 910.340 & 35.802
\end{tabular}

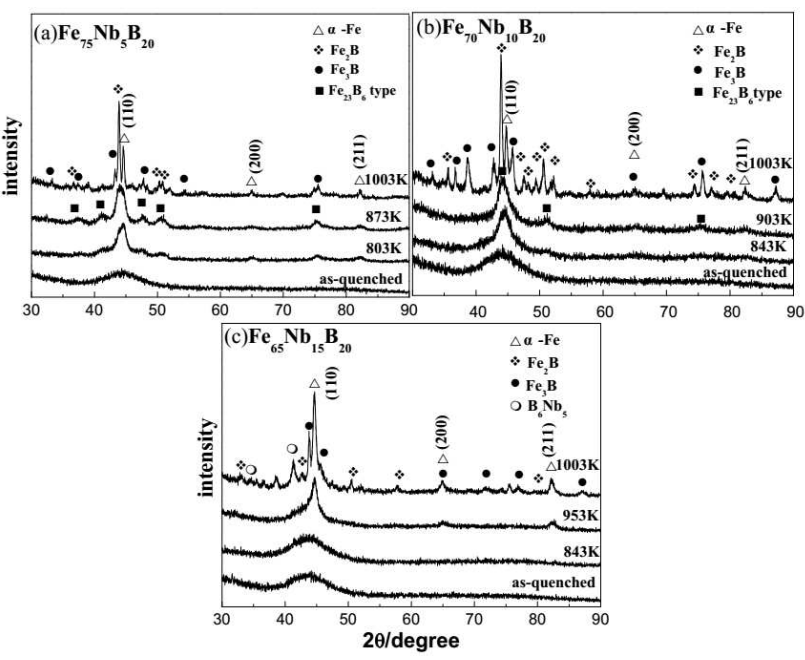

Fig. 4. XRD patterns of as-quenched and annealed $\mathrm{Fe}_{80-x} \mathrm{Nb}_{x} \mathrm{~B}_{20}(x=5,10,15)$ ribbons.

ribbons are all amorphous. FeNbB system is favored in the three empirical rules [12]. FeNbB system consists of three components ( $\mathrm{Fe}, \mathrm{Nb}$ and $\mathrm{B}$ ). There is significant difference in atomic size ratios above $12 \%$ among the main constituent elements and the sequence of atomic size is $R_{\mathrm{Nb}}(0.198 \mathrm{~nm})>R_{\mathrm{Fe}}(0.156 \mathrm{~nm})>R_{\mathrm{B}}(0.087 \mathrm{~nm})$. The negative heats of mixing of $\mathrm{Fe}-\mathrm{B}, \mathrm{Nb}-\mathrm{Fe}$, and $\mathrm{Nb}-\mathrm{B}$ are $-26,-16$ and $-54 \mathrm{~kJ} / \mathrm{mol}[13]$, respectively. This system has high negative heats of mixing.

The primary stage of crystallization of the three ribbons changes with $\mathrm{Nb}$ content addition. The primary devitrification phase of $\mathrm{Fe}_{70} \mathrm{Nb}_{10} \mathrm{~B}_{20}$ and $\mathrm{Fe}_{75} \mathrm{Nb}_{5} \mathrm{~B}_{20}$ are similar, which is the metastable phase of $\mathrm{Fe}_{23} \mathrm{~B}_{6}$ type. It seems that the $\mathrm{Fe}_{23} \mathrm{~B}_{6}$ type was formed by annealing at lower temperatures, $843 \mathrm{~K}$ for $\mathrm{Fe}_{70} \mathrm{Nb}_{10} \mathrm{~B}_{20}$ and $803 \mathrm{~K}$ for $\mathrm{Fe}_{75} \mathrm{Nb}_{5} \mathrm{~B}_{20}$, which coincides with the results of Imafuku et al. [14]. $\mathrm{Fe}_{65} \mathrm{Nb}_{15} \mathrm{~B}_{20}$ is still in amorphous state at $843 \mathrm{~K}$, which is related to its high thermal stability. The primary devitrification phase of $\mathrm{Fe}_{65} \mathrm{Nb}_{15} \mathrm{~B}_{20}$ is very different from $\mathrm{Fe}_{70} \mathrm{Nb}_{10} \mathrm{~B}_{20}$ and $\mathrm{Fe}_{75} \mathrm{Nb}_{5} \mathrm{~B}_{20}$. The primary devitrification phase of the $\mathrm{Fe}_{65} \mathrm{Nb}_{15} \mathrm{~B}_{20}$ is $\alpha$-Fe type crystalline phase.

Figure 5 shows the hysteresis loops of as-quenched $\mathrm{Fe}_{80-x} \mathrm{Nb}_{x} \mathrm{~B}_{20} \quad(x=5,10,15)$ ribbons at room-temperature. $\mathrm{Fe}_{80-x} \mathrm{Nb}_{x} \mathrm{~B}_{20}(x=5,10)$ ribbons are ferromagnetic and $\mathrm{Fe}_{65} \mathrm{Nb}_{15} \mathrm{~B}_{20}$ ribbon is paramagnetic. The inset shows the $M-T$ curve of $\mathrm{Fe}_{65} \mathrm{Nb}_{15} \mathrm{~B}_{20}$ ribbon at low temperature. The Curie temperature of $\mathrm{Fe}_{65} \mathrm{Nb}_{15} \mathrm{~B}_{20}$ 


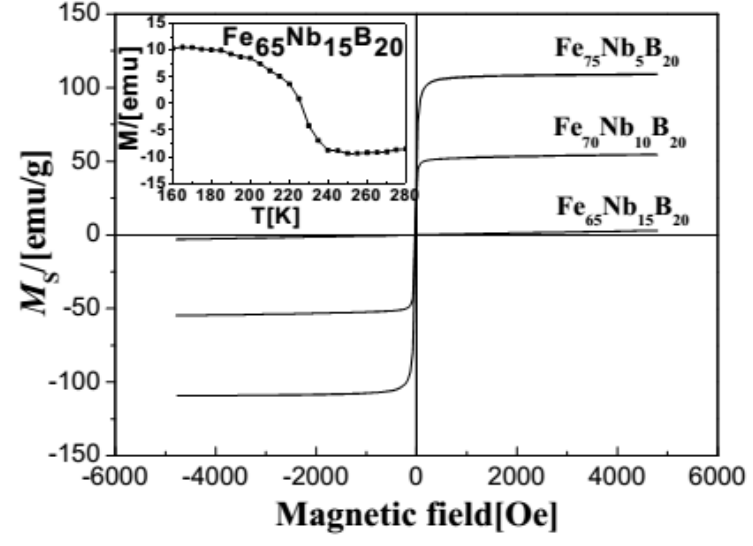

Fig. 5. The hysteresis loops of $\mathrm{Fe}_{80-x} \mathrm{Nb}_{x} \mathrm{~B}_{20}(x=$ $5,10,15)$ ribbons as-quenched at room temperature. The inset shows the $M-T$ curve of $\mathrm{Fe}_{65} \mathrm{Nb}_{15} \mathrm{~B}_{20}$ ribbon at low temperature.

ribbon is $225 \mathrm{~K}$. The saturation magnetization $\left(\boldsymbol{M}_{\mathrm{s}}\right)$ decreases with increasing $\mathrm{Nb}$ content. The variation can be related to the variation in the magnetic moment. On the one hand, due to the Fe substitution for $\mathrm{Nb}$, the Fe content decreases, so the magnetic moment of sample decreases. On the other hand, the variation of $\boldsymbol{M}_{\mathrm{s}}$ is related to the competition between ferromagnetic and antiferromagnetic exchange interaction. Antiferromagnetic coupling was formed between $\mathrm{Fe}$ and $\mathrm{Nb}$ [15]. Antiferromagnetic exchange interaction increases and ferromagnetic exchange interaction decreases with increasing $\mathrm{Nb}$ content, so $\boldsymbol{M}_{\mathrm{s}}$ decreases [16].

\section{Conclusions}

(1) The apparent activation energies of the $\mathrm{Fe}_{80-x} \mathrm{Nb}_{x} \mathrm{~B}_{20} \quad(x=5,10,15)$ ribbons are 414.9, 323.0 , and $425.7 \mathrm{~kJ} / \mathrm{mol}$, respectively. The thermal stability is the lowest for $\mathrm{Fe}_{70} \mathrm{Nb}_{10} \mathrm{~B}_{20}$ ribbon and the highest for $\mathrm{Fe}_{65} \mathrm{Nb}_{15} \mathrm{~B}_{20}$ ribbon. Along with the increase of $\mathrm{Nb}$ content, the supercooled liquid region $\Delta T_{x}\left(\Delta T_{x}=T_{x}-T_{\mathrm{g}}\right)$ increases gradually, indicating that the amorphous formation ability improves.

(2) The primary devitrification phase is metastable $\mathrm{Fe}_{23} \mathrm{~B}_{6}$ type for $\mathrm{Fe}_{70} \mathrm{Nb}_{10} \mathrm{~B}_{20}$ and $\mathrm{Fe}_{75} \mathrm{Nb}_{5} \mathrm{~B}_{20}$ ribbons, which is formed by annealing at low temperatures: $843 \mathrm{~K}$ for $\mathrm{Fe}_{70} \mathrm{Nb}_{10} \mathrm{~B}_{20}$ ribbon and $803 \mathrm{~K}$ for $\mathrm{Fe}_{75} \mathrm{Nb}_{5} \mathrm{~B}_{20}$ ribbon. $\mathrm{Fe}_{65} \mathrm{Nb}_{15} \mathrm{~B}_{20}$ ribbon is still in the amorphous state at $843 \mathrm{~K}$, which is related to its high thermal stability. The primary devitrification phase is $\alpha$-Fe type for the $\mathrm{Fe}_{65} \mathrm{Nb}_{15} \mathrm{~B}_{20}$ ribbon.
(3) $\mathrm{Fe}_{80-x} \mathrm{Nb}_{x} \mathrm{~B}_{20}(x=5,10)$ ribbons are ferromagnetic and the $\mathrm{Fe}_{65} \mathrm{Nb}_{15} \mathrm{~B}_{20}$ ribbon is paramagnetic. The saturation magnetization $\left(\boldsymbol{M}_{\mathrm{s}}\right)$ decreases with increasing $\mathrm{Nb}$ content, which is related to the magnetic moment.

\section{Acknowledgments}

This work was funded by Science and Technology Development Project of Jilin Province (No. 201105083), Science and Technology Studying Project of "12th five-year" Office of Education of Jilin Province (No. 2011-158) and Graduate Innovative Research Programs of Jilin Normal University (No. 201103).

\section{References}

[1] W.Q. Yu, Y.M. Sun, L.H. Liu, L.R. Dong, Z. Hua, Acta Phys. Pol. A 120, 1034 (2011).

[2] A. Baron, D. Szewieczek, G. Nawrat, Electrochim. Acta 52, 5690 (2007)

[3] T. Tokunaga, K. Terashima, H. Ohtani, M. Hasebe Mater. Trans. 49, 2534 (2008).

[4] T. Tamura, D. Kamikihara, Y. Mizutani, K. Miwa, Mater. Trans. 47, 1360 (2006).

[5] H. Huang, G. Shao, P. Tsakiropoulos, J. Alloys Comp. 459, 185 (2008).

[6] M. Imafuku, S. Sato, H. Koshiba, E. Matsubara, A. Inoue, Mater. Trans. JIM 41, 1526 (2000).

[7] J. Torrens-Serra, P. Bruna, J. Rodríguez-Viejo, T. Pradell, M.T. Clavaguera-Mora, Rev. Adv. Mater. Sci. 18, 464 (2008).

[8] Y.H. Gao, D. Shindo, Phys. Rev. B 67, 172409 (2003).

[9] T. Itoi, A. Inoue, Mater. Trans. JIM 40, 643 (1999).

[10] Z. Stokłosa, J. Rasek, Phys. Status Solidi A 207, 452 (2010).

[11] H.E. Kissinger, Anal. Chem. 29, 1702 (1957).

[12] A. Inoue, A. Takeuchi, T. Zhang, Metall. Mater. Trans. A 29, 1779 (1998).

[13] A. Takeuchi, A. Inoue, Mater. Trans. 46, 2817 (2005).

[14] M. Imafuku, S. Sato, H. Koshiba, E. Matsubara, A. Inoue, Scr. Mater. 44, 2369 (2001).

[15] W.S. Zhan, B.G. Shen, J.G. Zhao, Acta Phys. Sin. 34, 1613 (1985).

[16] Y. Hu, L. Liu, K.C. Chan, M.X. Pan, W.H. Wang, Mater. Lett. 60, 1080 (2006). 